ORIGINAL ARTICLE

\title{
Education level inequalities and transportation injury mortality in the middle aged and elderly in European settings
}

\author{
C Borrell, A Plasència, M Huisman, G Costa, A Kunst, O Andersen, M Bopp, J-K Borgan, \\ P Deboosere, M Glickman, S Gadeyne, C Minder, E Regidor, T Spadea, T Valkonen, \\ J P Mackenbach
}

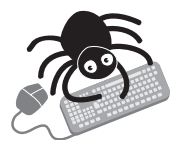

Table 1 can viewed on our website

See end of article for authors' affiliations

.....................

Correspondence to:

Dr C Borrell, Agència de Salut Pública de

Barcelona, Pl Lesseps 1 08023 Barcelona, Spain; cborrell@aspb.es

Accepted

13 December 2004
Objective: To study the differential distribution of transportation injury mortality by educational level in nine European settings, among people older than 30 years, during the 1990s.

Methods: Deaths of men and women older than 30 years from transportation injuries were studied. Rate differences and rate ratios (RR) between high and low educational level rates were obtained.

Results: Among men, those of low educational level had higher death rates in all settings, a pattern that was maintained in the different settings; no inequalities were found among women. Among men, in all the settings, the RR was higher in the $30-49$ age group (RR $1.46,95 \% \mathrm{Cl} 1.32$ to 1.61 ) than in the age groups $50-69$ and $\geqslant 70$ years, a pattern that was maintained in the different settings. For women for all the settings together, no differences were found among educational levels in the three age groups. In the different settings, only three had a high RR in the youngest age group, Finland (RR $1.33,95 \% \mathrm{Cl} 1.01$ to 1.74), Belgium (RR 1.38; $95 \% \mathrm{Cl} 1.13$ to 1.67), and Austria (RR 1.49, $95 \% \mathrm{Cl} 0.75$ to 2.96 ).

Conclusion: This study provides new evidence on the importance of socioeconomic inequalities in transportation injury mortality across Europe. This applies to men, but not to women. Greater attention should be placed on opportunities to select intervention strategies tailored to tackle socioeconomic inequalities in transportation injuries. t njuries are a major cause of death and disability, road traffic injuries being the ninth leading cause of worldwide disability adjusted life years, ${ }^{12}$ and in 2020 it is expected to be the sixth. ${ }^{1}$ However, the injury burden is not shared equally among all groups in society, with inequalities by socioeconomic position, the less privileged groups suffering higher rates of mortality and morbidity. ${ }^{3}$

The study of social inequalities in health has shown how people of low socioeconomic level have higher rates of mortality, morbidity, and disability. These studies are important for many reasons: (1) inequalities affect the whole population and not only the poor, (2) health inequalities are increasing because the health of advantaged classes improves more than the health of disadvantaged classes, and (3) it is possible to implement interventions in order to diminish these inequalities in health. Moreover, socioeconomic inequalities in health and in traffic injuries are important for reasons of fairness and social justice, and because targeting or tailoring injury prevention measures towards disadvantaged groups may increase the overall effectiveness of these measures. ${ }^{4}$ However, recent reports on traffic injuries have not highlighted the issue of socioeconomic inequalities in injuries.

Although the study of social inequalities in health has been broadened since the 1980s, inequalities in injuries have been studied somewhat less, ${ }^{3}$ and most studies, mainly of traffic injuries, have focused on children and the young. These studies show the existence of socioeconomic inequalities in injury mortality and morbidity, with less privileged children showing higher injury rates. ${ }^{6}$ Fewer studies have been done describing socioeconomic inequalities in mortality by injuries, and transportation/traffic injuries, in middle age and the elderly. ${ }^{3}$
Despite the increasing attention placed on the need to reduce the impact of motor vehicle injuries in Europe, ${ }^{7}$ no studies have examined such impact from the point of view of social inequalities in the European context. The objective of this paper is to study the differential distribution of transportation injury mortality by educational level in nine European settings, among middle aged and elderly men and women during the 1990s.

\section{METHODS}

We studied the population older than 30 years living in nine European settings. We used mortality data from an international study ("Socioeconomic determinants of healthy ageing: From description to explanation", SEdHA Study). Specifically, data from national, regional, and urban longitudinal mortality studies were used, ${ }^{8}$ based on the linkage between mortality registries and census data. We studied Austria, Belgium, Denmark, Finland, Norway, and Switzerland, the region of Madrid (Spain) and the cities of Turin (Italy) and Barcelona (Spain). For Switzerland we only included the population living in the German speaking parts of the country. The data refer to different settings (countries, regions, and cities) due to the availability of information in each country. In this study, we included cases of death older than 30 years from traffic injuries and other transport injuries (codes of the International Classification of Diseases (ICD)-8 revision: E800-E845 and E940-E941; ICD-9 codes E800-E848, E929.0, and E929.1, and ICD-10 codes V01-V99, Y85.0, and Y85.9) of residents in each of the participant countries or regions during the 1990s. The ICD codes chosen in the SedHA Study were the ones that played a major role in explaining inequalities in mortality among the 
elderly. For Denmark we only included people up to 69 years because we did not have data for older age groups.

The data were aggregated by five year age group (age specified at the start of the follow up), sex, and level of education. Person years at risk were obtained from the appropriate censuses.

As a measure of socioeconomic status, educational level of each deceased was used. ${ }^{9}$ It was obtained from the census and was coded initially according to national education classifications. We reclassified these into three categories (low, middle, and high), that corresponded approximately with levels $0-2$ (pre-primary, primary, and lower secondary education), 3 (upper secondary education), and 4-6 (postsecondary education) of the UNESCO Standard Classification scheme respectively. This reclassification is based on the relative position of the educational levels in the population and it resulted in a distribution of educational levels over the population that was similar and comparable across countries. ${ }^{8}{ }^{10}$ In the calculation of rate differences and rate ratios, we used the combined levels of middle and high education as the reference group. These levels were combined because in some settings the proportion of highly educated (the reference group) was too small in some age groups to perform robust analyses. Table l (see http://www.injuryprevention.com/ supplemental) shows the distribution of person years by educational level. For Switzerland applying the general classification proved difficult, as is apparent from deviating distribution over the population. ${ }^{8}$ Table 1 also shows the percentage of death records where the educational level was missing, which was most important in Barcelona (more or less 30\%) but also large in Madrid, Denmark, and Belgium (between $8 \%$ and $17 \%$ ). These percentages were similar for males and females. These deaths were not excluded from the calculation of total mortality transportation rates, but they had to be excluded from the educational level rates.
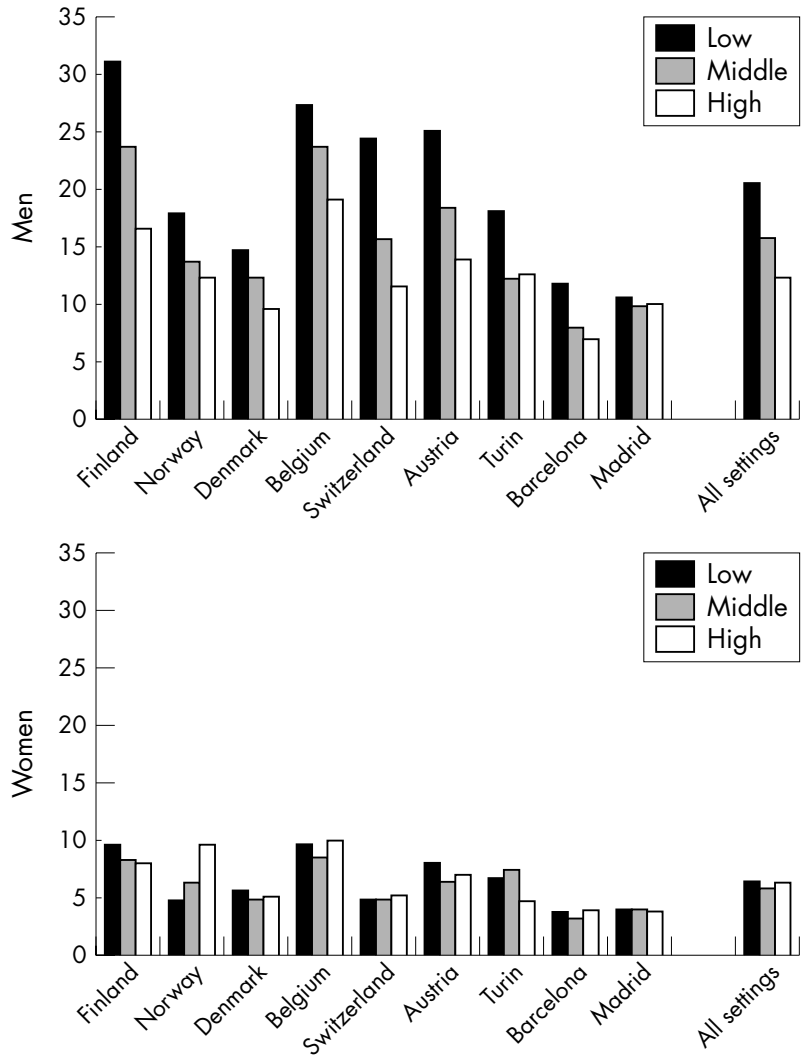

Figure 1 Standardized mortality rates per 100000 person years by educational level (three groups) by setting and sex. Transportation injuries mortality, $\geqslant 30$ years old. Data for Denmark refers to up to 69 years of age. Switzerland only includes German speaking parts. "All settings" excludes Denmark.

Table 2 Number of deaths (n), rates per 100000 person years (rate) and rate difference (RD) (low minus middle/high level of education) by setting, age group, and sex. Transportation injuries mortality, $\geqslant 30$ years old

\begin{tabular}{|c|c|c|c|c|c|c|c|c|c|c|c|c|}
\hline & \multicolumn{3}{|c|}{$30-49$ years } & \multicolumn{3}{|c|}{$50-69$ years } & \multicolumn{3}{|c|}{$\geqslant 70$ years } & \multicolumn{3}{|c|}{ Total $\geqslant 30$ years $*$} \\
\hline & $\mathbf{n}$ & Rate & RD & $\mathbf{n}$ & Rate & RD & $n$ & Rate & RD & $n$ & Rate & RD \\
\hline \multicolumn{13}{|l|}{ Men } \\
\hline Finland & 782 & 19.88 & 11.10 & 609 & 27.23 & 6.03 & 303 & 51.51 & 19.68 & 1694 & 25.07 & 13.77 \\
\hline Norway & 394 & 13.06 & 7.23 & 330 & 18.00 & 1.99 & 216 & 27.96 & 4.41 & 940 & 16.72 & 7.27 \\
\hline Denmark & 519 & 13.68 & 3.92 & 410 & 17.34 & 3.43 & - & - & - & 929 & 15.09 & 4.27 \\
\hline Belgium & 1637 & 24.17 & 8.43 & 1011 & 20.69 & 2.77 & 581 & 41.83 & 5.25 & 3229 & 24.75 & 7.05 \\
\hline Switzerland $†$ & 357 & 12.07 & 8.15 & 292 & 14.96 & 13.18 & 299 & 39.14 & 10.74 & 948 & 16.71 & 14.70 \\
\hline Austria & 207 & 18.93 & 10.85 & 163 & 21.57 & 10.99 & 107 & 43.92 & -1.77 & 477 & 22.79 & 10.12 \\
\hline Turin & 60 & 10.41 & 2.01 & 91 & 16.41 & 1.19 & 63 & 43.31 & 35.38 & 214 & 16.77 & 7.55 \\
\hline Barcelona & 125 & 12.43 & 1.73 & 87 & 9.76 & 1.08 & 100 & 27.30 & 5.14 & 312 & 13.78 & 3.20 \\
\hline Madrid & 116 & 10.76 & 1.91 & 81 & 11.14 & 0.32 & 29 & 11.99 & -4.40 & 226 & 11.04 & 1.05 \\
\hline All settingsł & & 14.43 & 5.37 & & 16.93 & 4.59 & & 35.29 & 6.58 & & 18.59 & 6.94 \\
\hline \multicolumn{13}{|l|}{ Women } \\
\hline Finland & 218 & 5.75 & 1.72 & 259 & 9.87 & 2.57 & 244 & 19.13 & 1.60 & 721 & 9.38 & 5.21 \\
\hline Norway & 93 & 3.23 & -0.04 & 113 & 5.71 & -2.67 & 127 & 10.17 & -9.74 & 333 & 5.45 & 0.17 \\
\hline Denmark & 161 & 4.38 & 0.24 & 206 & 8.03 & 1.23 & - & - & - & 367 & 5.88 & 1.70 \\
\hline Belgium & 467 & 7.08 & 2.26 & 522 & 9.60 & -0.01 & 399 & 15.60 & -3.55 & 1388 & 9.51 & 2.78 \\
\hline Switzerland $\dagger$ & 83 & 2.68 & 0.39 & 117 & 5.01 & 1.11 & 168 & 12.80 & -3.62 & 368 & 5.45 & 2.01 \\
\hline Austria & 42 & 3.94 & 1.47 & 75 & 8.45 & 0.78 & 113 & 22.35 & 5.36 & 230 & 9.35 & 4.32 \\
\hline Turin & 27 & 4.46 & -1.31 & 45 & 6.93 & -0.94 & 48 & 17.31 & 9.98 & 120 & 7.83 & 2.19 \\
\hline Barcelona & 47 & 4.32 & 0.19 & 51 & 4.85 & 0.15 & 65 & 9.83 & -2.73 & 163 & 5.82 & 1.27 \\
\hline Madrid & 36 & 3.12 & 0.05 & 43 & 5.21 & -0.18 & 28 & 6.66 & 0.58 & 107 & 4.46 & 1.01 \\
\hline All settings $\ddagger$ & & 4.01 & 0.48 & & 6.67 & 0.46 & & 13.97 & -0.74 & & 7.21 & 2.29 \\
\hline
\end{tabular}


Table 3 Rate ratios (RR) of mortality comparing low versus middle/high level of education, by setting, age group, and sex. Transportation injuries mortality, $\geqslant 30$ years old

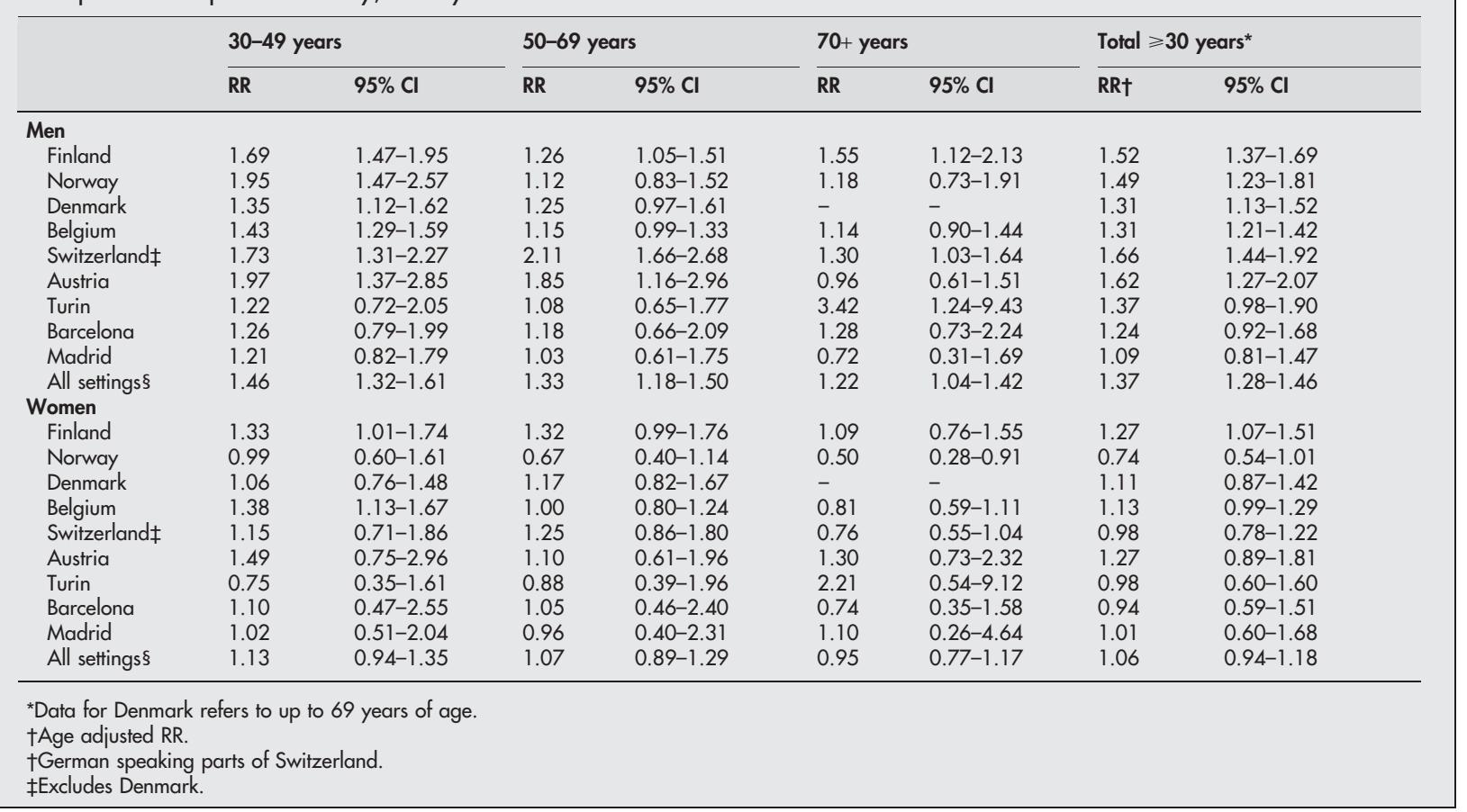

Age standardised rates for each of the three educational levels in each setting were calculated by the direct method using as standard the European population. ${ }^{11}$ Mortality rates by age group $(30-49,50-69, \geqslant 70)$ and sex were obtained for each setting. For Denmark all these analyses were obtained only for people younger than 70 years of age.

We created a pooled dataset with the data of all settings, including setting specific weights assigned to the individual observations, so that the separate populations carried equal weight in the results for all populations combined. The dataset included all settings with the exception of Denmark (because of missing data for older people).

Absolute educational mortality inequalities were expressed as rate differences for each setting and sex. Rate ratios (RR) were also determined for the same groups through Poisson regression models ${ }^{12}$ in order to study relative inequalities in mortality. We used SPSS (SPSS In, Chicago, IL, USA) and Egret statistical packages (Egret, Cytel Software Corp, 1999).

\section{RESULTS}

Transportation injuries death rates increased with age and in men were higher than in women (table 2). For men as well as for women, Finland, Belgium, and Austria had the highest death rates.

Figure 1 shows the age standardized death rates among the three educational levels in males and females in each setting and in all settings together. In men, those with a low educational level had higher death rates in all settings (death rate of 20.5 per 100000 inhabitants, compared with a rate of 12.3 in the high level education), a pattern that was maintained in the different settings although in Madrid the differences were very small. Inequalities were most important in Finland, where the death rate of 31.1 per 100000 inhabitants among men of low educational level contrasts with 16.5 among men of high educational level. There were no significant differences in women (death rates around six per 100000 inhabitants in the three levels of education) and in some countries a reverse pattern was observed, for example in Norway where high educational levels had higher rates (7.1 per 100000 inhabitants among women with a high level of education and 4.1 with a low level).

Differences between rates in the two groups of educational level by setting, age group, and sex are shown in table 2 . For all the settings the differences are around five per 100000 inhabitants in males, increasing in the elderly, and they are small in females. In the different settings, for men, the biggest differences are found in Finland, Switzerland, and Austria, whereas for women the differences are very small and for the oldest group, the majority of differences are negative.

Rate ratios by country, age group, and sex are presented in table 3. Among men, in all the settings, the RR was higher in the 30-49 age group (RR 1.46, 95\% CI 1.32 to 1.61 ) than in the other age groups. In the youngest group, the majority of RR of the different settings were higher than 1 and statistically significant, except for the region and cities of the South of Europe. In the 50-69 age group for males it is worth mentioning the highest rate ratios for Switzerland (RR $2.11,95 \%$ CI 1.66 to 2.68 ) and Austria (RR 1.85, 95\% CI 1.16 to 2.96$)$. In the oldest age group the RR were lower.

For women in all the settings together, no differences were found among educational levels in the three age groups. In the different settings, only three had a high RR in the youngest age group, Finland (RR 1.33, 95\% CI 1.01 to 1.74 ), Belgium (RR 1.38, 95\% CI 1.13 to 1.67), and Austria (RR 1.49, $95 \%$ CI 0.75 to 2.96), while in Norway women older than 50 years had a statistically significant RR under 1 (table 3 ).

\section{DISCUSSION}

This study is the first attempt to compare the differential impact of transportation/traffic fatalities by education among different European settings. The results indicate that educational inequalities were more important in younger adult males (age 30-49 years). On the contrary, female transportation/traffic mortality showed no inequalities in the majority of settings, with a reversed trend in the oldest age group in some settings. 
A conceptual framework has been proposed for studying the impact on injury of socioeconomic level and social context. $^{6}$ At an individual level, two mechanisms may be involved in the relation between socioeconomic level and injury: differential exposure (for example, different use of protective devices by people of different socioeconomic level) and differential susceptibility. The influences of the social context may have an impact on socioeconomic level, differential exposure, differential susceptibility and directly on injury. In this paper, we have been able to measure socioeconomic level through educational level and also contextual influences by means of the different national contexts.

The differences found in the transportation/traffic mortality rates in the various settings are worthy of comment. Although it has been reported previously, in national statistics, ${ }^{13}$ that southern European countries have higher traffic injury death rates than the majority of central and northern countries, in this study the rates for settings in the south of Europe are the lowest. We believe that this is at least partly because these data come from urban areas (Madrid, Turin, and Barcelona), where traffic exposure patterns are somewhat different. Injury severity tends to be lower in urban areas, where traffic crashes tend to be at a lower speed and therefore the resulting impact tends to be less harmful, possibly contributing to lower overall rates and smaller educational differences. However, it is uncertain whether and how this fact would affect the comparability of relative inequalities among the different settings. Moreover, it has to be mentioned that Switzerland only included German speaking population.

Another study has described how economic development of a country is related to traffic mortality: it first leads to a growing number of traffic deaths but later becomes protective, although some countries do not clearly follow this pattern, such as Spain and Greece, where no decrease in traffic deaths was found. ${ }^{14}$ However, this study did not focus on socioeconomic inequalities in health.

The interpretation of the differential impact of transportation/traffic mortality by educational level needs to account for the differential exposure to traffic of people of different educational levels, a feature that the study could not cover due to the lack of information on exposure levels, such as number of vehicles, kilometers driven, and so on. Although there is evidence indicating that exposure to traffic tends to be higher in men and in the young and middle age population, ${ }^{15}{ }^{16}$ there is limited direct evidence that the less educated population generally undergoes a more intense exposure to traffic. Nevertheless, possible explanations for mortality differences include the fact that people of lower socioeconomic status (with less education) are less likely to be able to afford new cars, use protective devices, and are more likely to live in inner city areas, where pedestrian risk of injury is higher. ${ }^{17}$ In fatally injured passenger vehicle drivers in the US, Braver has found higher percentages of blood alcohol concentration and of failure to use a seat belt among people with lower socioeconomic status. ${ }^{18}$ Elderly people of lower socioeconomic status are less likely to be car owners and more likely to live in inner city areas, and therefore have higher risk of being injured as a pedestrian than the more privileged.

The observed sex differences in mortality are likely to be largely related with differences in exposure to traffic, as shown in most settings, as well as to risk factors for injury such as alcohol use or use of protective devices. Another possible aspect explaining male-female inequalities may be related to the social construction of masculinity (how men "are supposed" to behave in our society), implying that men undertake more risky behaviors such as driving more dangerously. ${ }^{19}$ If, to demonstrate masculinity, men of different social classes undertake different unhealthy behaviors, ${ }^{20}$ then men of different social classes may engage in different degrees of risky driving (high speed, not wearing protective devices, going through red lights, and so on). The lack of inequalities among women of different educational levels may be due to the fact that differences in exposure to traffic and risk factors among women of different educational levels are minimal. ${ }^{18}$

Most studies done in other settings on inequalities in traffic injury mortality in children and adolescents have found that people belonging to disadvantaged social classes and living in socioeconomically deprived areas are at greater risk of injury, ${ }^{3}$ findings also applying to the different kinds of road users-inequalities being greatest for injuries involving motorised vehicles. ${ }^{21}$ Other studies in the adult population have also revealed inequalities by socioeconomic status finding gradients for women as well as for men, although the gradients were steeper for men. ${ }^{3} 17182223$

Several limitations of this study have to be taken into account. The first is that it was not possible, from the available data, to identify the death rates of drivers, passengers, and pedestrians separately. This greater level of detail would be desirable both to improve our ability to explain the patterns of inequality found, and for the appropriate formulation of preventive interventions. In two settings where we could check it for a reasonable percentage of deaths $(70 \%)$ through the fourth digit of the ICD-9 code of the cause of death (Barcelona) and the fourth digit of the ICD-8 and the third digit of the ICD-10 (Switzerland), we were able to verify that pedestrians were mainly older people $(\geqslant 70$ years) and women. We cannot rule out the hypothesis that inequalities in mortality among pedestrians are not the same as for vehicle users. Future studies should try to investigate traffic mortality inequalities separating these groups.

Secondly, it should be noted that there could be differences in reporting traffic injury mortality across countries, ${ }^{24}$ but we do not know if they change by socioeconomic level. A study on improvement of the quality and comparability of causes of death statistics inside the European Union stated the importance of improving information on causes of death of "accidental deaths". ${ }^{25}$

Finally, it is also noteworthy that it is in some of the southern European settings that information on educational level was more often missing, although there is no evidence that this may be related to socioeconomic variables, hence the $\mathrm{RR}$ are not biased, although the rate differences may be somewhat infraestimated.

\section{IMPLICATIONS FOR PREVENTION}

This study provides new evidence on the importance of socioeconomic inequalities in transportation injury mortality in men across Europe, which need to be taken into account as part of the already heavy burden of traffic injuries on health in society. No such inequalities have been found among women. Although there is a clear need to study more deeply the causes of these inequalities, such as differential exposures and risk factors among educational levels and sex, greater attention should be given to opportunities to select intervention strategies that are effective to tackle socioeconomic inequalities in transportation/traffic injuries. ${ }^{26}{ }^{27}$ Examples of these strategies are pre-crash preventive strategies tailored to disadvantaged groups, such as health promotion programs with culturally and linguistically appropriate messages for the groups with low educational level. Similarly, interventions on the physical environment, such as traffic calming and pedestrian protection initiatives, should focus on places and areas where crashes cause most victims among lower 
socioeconomic groups. As an example of post-crash strategies we should mention the improvement of access to care and to rehabilitation services to the whole population, including the disadvantaged groups. ${ }^{26}$

\section{ACKNOWLEDGEMENTS}

This study is based on a grant (contract QLK6-CT-1999-02161) from the Fifth Framework Programme on "Quality of Life and Management of Living Resources" of the European Union. The construction of the Swiss National Cohort has been supported by the Swiss National Science Foundation, grants No 32-5884.98 and 32-63625.00.

\section{Authors' affiliations \\ C Borrell, A Plasència, Agència de Salut Pública de Barcelona, \\ Barcelona, Spain}

A Plasència, Universitat Autònoma de Barcelona, Barcelona, Spain

M Huisman, A Kunst, J P Mackenbach, Department of Public Health, Erasmus MC, University Medical Center, Rotterdam, the Netherlands G Costa, T Spadea, Department of Public Health and Microbiology, University of Turin, Turin, Italy

O Andersen, Research and Methodology, Statistics Denmark, Copenhagen, Denmark

M Bopp, Institute for Social and Preventive Medicine, University of Zurich, Zurich, Switzerland

J-K Borgan, Division for Health Statistics, Statistics Norway, Oslo, Norway

P Deboosere, S Gadeyne, Interface Demography, Free University Brussels, Brussels, Belgium

M Glickman, Health and Care Division, Office for National Statistics, London, UK

C Minder, Institute for Social and Preventive Medicine, University of

Bern, Switzerland

E Regidor, Department of Preventive Medicine and Public Health, University of Madrid, Madrid, Spain

T Valkonen, Department of Sociology, University of Helsinki, Helsinki, Finland

\section{REFERENCES}

1 Murray CJL, Lopez AD. Alternative projections of mortality and disability by cause 1990-2020: Global Burden of Disease Study. Lancet 1997;349:1498-504

2 Murray CJL, Lopez AD. Global mortality, disability and the contribution of risk factors: Global Burden of Diseases Study. Lancet 1997;349:1436-42.

3 Cubbin C, Smith GS. Socioeconomic inequalities in injury: critical issues in design and analysis. Annu Rev Public Health 2002;23:349-75.

4 Evans T, Whitehead M, Diderichsen F, et al. Challenging inequities in health: from ethics to action. New York: Oxford University Press, 2001.
5 Thacker SB, MacKenzie EJ. Preface: the role of epidemiologist in Injury Prevention and Control-an unmet challenge. Epidemiol Rev 2003;25:1-2.

6 Laflamme I, Diderichsen F. Social differences in traffic injury risks in childhood and youth - a literature review and research agenda. Inj Prev 2000;6:293-8.

7 European Commission. White Paper: European transport policy for 2010: time to decide", 2001. Available at http://europa.eu.int/comm/ energy_transport/en/lb_en.html (accessed 8 April 2005)

8 Huisman M, Kunst AE, Andersen O, et al. Socio-economic inequalities in mortality among the elderly in ten European populations. J Epidemiol Community Health 2004;58:468-75.

9 Krieger N, Williams DR, Moss NE. Measuring social class in US public health research: concepts, methodologies and guidelines. Annu Rev Public Health 1997; 18:341-78.

10 Avendaño $M$, Kunst $A E$, Huisman $M$, et al. Educational level and stroke mortality. A comparison of 10 European Populations during the 1990s. Stroke 2004;35:432-7.

11 Eurostat. Demographic Statistics 1997. Luxembourg: Office for Official Publications of the European Communities, 1997.

12 Breslow NE, Day NE. Statistical methods in cancer research, vol. II. The analysis of cohort studies. Lyon: IARC Scientific Publications No 82, 1987:119-76.

13 WHO. World Health Statistics Annual, 1996. Geneve: WHO, 1998.

14 Beeck EF, Borsboom GJJ, Mackenbach JP. Economic development and traffic accident mortality in the industrialized world, 1962-1990. Int J Epidemiol 2000;29:503-9.

15 Kweon YJ, Kockelman KM. Overall injury risk to different drivers: combining exposure, frequency, and severity models. Accid Anal Prev 2003;35:441-50.

16 Li G, Baker SP, Langlois JA, et al. Are female drivers safer? An application of the decomposition method. Epidemiology 1998;9:379-84.

17 Cubbin C, LeClere FB, Smith GB. Socioeconomic status and the occurrence of fatal and nonfatal injury in the United States. Am J Public Health 2000;90:70-7.

18 Braver ER. Race, Hispanic origin and socioeconomic status in relation to motor veh/icle occupant death rates and risk factors among adults. Accid Analysis Prev 3003;35:295-309

19 Doyal L. Sex, gender, and health: the need for a new approach. BMJ 2001;323:1061-3.

20 Courtenay WH. Constructions of masculinity and their influence on men's well-being: a theory of gender and health. Soc Sci Med 2000;50:1385-401

21 Hasselberg M, Laflamme L, Ringbäck Weitoft G. Socioeconomic differences in road traffic injuries during childhood and youth: a closer look at different kinds of road user. J Epidemiol Community Health 2001;55:858-62.

22 Cubbin C, LeClere FB, Smith GS. Socioeconomic status and injury mortality: individual and neighborhood determinants. J Epidemiol Community Health 2000;54:517-24.

23 Borrell C, Rodríguez M, Ferrando J, et al. The role of individual and contextual effects in injury mortality: new evidence from small area analysis. Inj Prev 2002;8:297-302.

24 Fingerhut LA, Cox CS, Warner M. International comparative analysis of injury mortality findings from the ICE on Injury Statistics. Adv Data 1998;303:1-20.

25 Jougla E, Pavillon G, Rossollin F, et al. Improvement of the quality and comparability of causes-of-death statistics inside the European Community. Rev Epidem et Sante Publ 1998;46:447-56.

26 Plasència A, Borrell C. Reducing socioeconomic inequalities in road traffic injuries: time for a policy agenda. J Epidemiol Community Health 2001;55:853-54.

27 Hyder AA, Peden M. Inequality and road traffic injuries: call for action. Lancet 2003;362:2034-5

\section{LACUNAE}

\section{New Zealand drowning report}

A recent report, Circumstances surrounding drowning in those under 25 years in New Zealand (1980-2002), from New Zealand's Child and Youth Mortality Review Committee in collaboration with Water Safety NZ reveals that there has been a significant reduction in the incidence of drowning related deaths $(p<0.001)$. The study reviewed the 1334 drowning related deaths over the 23 year study period. It identified that the areas needing further attention are pre-school drownings and drownings of males aged 15-19. The authors also emphasise the need to enforce pool fencing legislation and to increase water safety education. For further information, contact Professor Barry Taylor, Professor of Paediatrics and Child Health, at the Dunedin School of Medicine, email: barry.taylor@stonebow. otago.ac.nz. 